\title{
Effects of swimming training on myocardial protection in rats
}

\author{
CHANG-CHI LAI ${ }^{1}$, CHIA-YU TANG ${ }^{2}$, SZU-KAI FU ${ }^{3}$, WEI-CHIN TSENG ${ }^{1}$ and KUO-WEI TSENG ${ }^{1}$ \\ ${ }^{1}$ Department of Exercise and Health Sciences, University of Taipei, Taipei $11153 ;{ }^{2}$ Department of Physical Education, \\ Chang Gung University, Taoyuan $33302 ;{ }^{3}$ Graduate Institute of Sports Training, \\ University of Taipei, Taipei 11153, Taiwan, R.O.C.
}

Received September 18,2021; Accepted December 23, 2021

DOI: 10.3892/br.2022.1502

\begin{abstract}
Swimming is important for promoting and maintaining health, as it can increase the efficiency of the cardiovascular system and decrease the occurrence of cardiovascular diseases. The objective of the present study was to examine whether swimming training could decrease myocardial injury in rats caused by myocardial ischemia/reperfusion (I/R). Sprague-Dawley rats were randomized into four groups, namely the Sham, coronary artery occlusion, swimming training and ischemic preconditioning (IPC) groups. Myocardial I/R was induced in anesthetized male Sprague-Dawley rats by a 40-min occlusion followed by a 3-h reperfusion of the left anterior descending coronary artery. The rats were sacrificed after surgery and their hearts were examined. The results demonstrated that the number of TUNEL-positive nuclei and degree of caspase-3 activation were both significantly increased in the myocardium following myocardial I/R in rats, indicating increased cardiomyocyte apoptosis. On the other hand, swimming training decreased the serum levels of creatine phosphokinase, lactate dehydrogenase and cardiac troponin I, and was associated with reduced histological damage and myocardial infarct size. Furthermore, swimming training also reduced TNF- $\alpha$ levels, caspase- 3 activation and enhanced $\mathrm{Bcl}-2$ activation, which decreased the number of apoptotic cells in the myocardium. The findings of the present study showed that swimming training and IPC could similarly decrease myocardial injury following myocardial I/R, and may therefore be used as exercise training to effectively prevent myocardial injury.
\end{abstract}

\section{Introduction}

The World Health Organization (2019) reported that heart disease, stroke and other cardiovascular diseases are

Correspondence to: Dr Kuo-Wei Tseng, Department of Exercise and Health Sciences, University of Taipei, 101, Section 2, Zhongcheng Road, Shilin, Taipei 11153, Taiwan, R.O.C.

E-mail: fossi10405@yahoo.com.tw

Key words: swimming training, myocardial ischemia-reperfusion, ischemic precondition, coronary artery occlusion, apoptosis the most frequent causes of death, with ischemic heart disease (IHD) accounting for the largest number of cardiovascular diseases-related deaths $(1,2)$. The Global Burden of Disease (GBD) study from 2016 stated that IHD and stroke are both types of cardiovascular diseases, and cardiovascular diseases overall are categorized as the leading cause of death in humans (2).

IHD refers to heart disease caused by insufficient blood circulation due to coronary artery stenosis, which manifests as decreased blood perfusion of the heart, resulting in myocardial ischemia, decreased metabolism and abnormal cardiac function $(3,4)$. When the vascular diameter decreases or occlusion occurs due to coronary artery endothelial cell thickening, lipid deposition or thrombosis, an imbalance develops between myocardial oxygen supply and demand, which further causes cardiomyocyte apoptosis or necrosis (5). Therefore, cardiac blood flow should be restored as soon as possible after myocardial ischemia to prevent myocardial necrosis; however, myocardial ischemia/reperfusion (I/R) also damages cardiomyocytes, which is termed myocardial I/R injury (MIRI) (6). MIRI is known to be associated with the incidence and mortality rate of cardiovascular diseases (7), as the myocardium develops biochemical and metabolic alterations during I/R. These include rapid intracellular ATP exhaustion, calcium overload leading to cell membrane disruption, synthesis of a large number of reactive oxygen species (ROS) and a decreased mitochondrial membrane potential, leading to caspase-3 activation and myocardial hypercontracture (8-11), thereby leading to cardiomyocyte death.

Ischemic preconditioning (IPC), one of the most common methods used to decrease the severity of myocardial injury in myocardial infarction (MI) studies, refers to administration of transient non-lethal infarction stimulation prior to the occurrence of fatal myocardial ischemia events. This stimulation induces immune system mechanisms and releases endogenous protective substances, such as adenosine, bradykinin and nitric oxide, to protect the myocardium and preserve energy metabolism, thereby decreasing the damage caused as well as the risk of fatal infarction $(12,13)$. IPC in vivo has predominantly been performed in animal studies, and the earliest study by Murry et al (14) found that IPC could protect the myocardium against persistent ischemic injury and reduce the infarct size (14-17). Subsequently, several studies have employed IPC in a number of animal experiments, such as rabbit, rat, murine and swine animal models, and proved that IPC protected the 
heart after MIRI, and also protected against abnormal systolic function and arrhythmia after ischemia (18-21).

Exercise is key for promoting and maintaining human health. Regular aerobic exercise can promote metabolism, improve hormone equilibrium, improve cognitive function, and it is also an important factor that controls cardiovascular disease $(22,23)$. It is well known that exercise can improve systemic circulation to increase cardiopulmonary function, increase coronary artery perfusion and improve cardiac tolerance (24-26).

It was previously demonstrated that exercise can be beneficial to myocardial function, as it can increase the ventricular dimensions, myocardial mass, cardiac output and stroke volume $(27,28)$. The effect of exercise training on MI was first evidenced in the study by McElroy et al (29). They found that the formation of new blood vessels in the hearts of rats after exercise reduced the infarct size after MI. In animals, running on a treadmill and swimming are primarily employed as interventional methods. For example, rats that undergo treadmill training are shown to have improved recovery in blood pumping capacity following myocardial ischemia, and they also exhibit increased levels of cardiac antioxidant enzymes, which decrease lipid peroxidation $(30,31)$. Swimming can increase cardiac antioxidant capacity in rats and improve the systolic function of the aged myocardium. In addition, swimming training prior to MI can increase cardiac arteriole density and aid in improving cardiac function at the remodeling phase (32-34).

Reducing cell death and myocardial injury caused by IHD and MIRI has been an important focus of research. Mitochondrial dysfunction following MIRI can induce apoptotic cell death, since the mitochondrial apoptogenic factor, cytochrome $c$, is released into the cytoplasm to activate caspase-3-mediated apoptosis (35); however, cytochrome $c$ leakage to the cytosol can be inhibited by Bcl-2/Bcl-xL (36). Furthermore, myocardial I/R causes the release of TNF- $\alpha$, which is a proinflammatory cytokine that exacerbates MIRI at an early stage of reperfusion by activating NF- $\kappa \mathrm{B}$, facilitating leukocyte infiltration and inducing apoptosis $(37,38)$. Animal experiments were performed in the present study to examine whether exercise intervention could protect against cardiovascular disease and to explore the roles of apoptotic signaling elements, such as TNF- $\alpha$, activated caspase- 3 and Bcl-2. The findings of the present study may lead to optimization of exercise programming for healthy individuals, athletes and patients with heart failure seeking strategies to enhance cardiac function (39).

\section{Materials and methods}

Ethics approval. The present study was approved by the Animal Experiment Committee of University of Taipei (Taipei, Taiwan; IACUC approval no. UT110001). The animals used in the study were managed in a humane manner in accordance with the Guide for the Care and Use of Laboratory Animals (40).

Animal preparation. A total of 42 Sprague-Dawley male rats, which were purchased from BioLASCO, and weighed 250-280 g, were used in the present study. A total of 1 week prior to the experiment, the rats were moved to the laboratory to allow them to acclimate. The rats were given ad libitum access to food and water, and maintained with a $12 \mathrm{~h}$ light/dark cycle from 6:00 a.m. to 6:00 p.m., and the room temperature was controlled at $25^{\circ} \mathrm{C}$ and a humidity of $55 \pm 5 \%$.

The rats were randomly assigned to one of four groups as follows: Sham control group (Sham, $n=10$ ), myocardial ischemia group (coronary artery occlusion; CAO, $n=10$ ), swimming training group $(\mathrm{EXC}, \mathrm{n}=10)$ and IPC group (IPC, $\mathrm{n}=10$ ). Rats in the EXC group were allowed to acclimate to swimming training at the age of 3 weeks. Swimming started at $15 \mathrm{~min}$ per day and was increased to $180 \mathrm{~min}$ per day at day 6 . At 4-7 weeks of age, the rats underwent $3 \mathrm{~h}$ of swimming training per day. Water temperature was controlled at $35-37^{\circ} \mathrm{C}$. The forced swimming test procedure was employed for swimming training (41). Since the forced swimming test procedure was employed in the swimming training, the rats were kept in the status of swimming throughout the training period in which they could not reach the bottom or hang on the side with the continued supervision of the experimenters. In other words, the time of immobility and climbing while the rats in the water was completely excluded.

Experimental protocol. The rats were anesthetized by intraperitoneal injection of $20 \mathrm{mg} / \mathrm{kg}$ BW Zoletil 50 [tiletamine + zolezepam; Virbac (Taiwan) Co., Ltd.] and intraperitoneal injection of $10 \mathrm{mg} / \mathrm{kg}$ BW Balanzine (xylazine 2\% w/v) (42). After tracheotomy, each rat was intubated and ventilated, and the carotid artery was cannulated for the direct BP measurement. Throughout the experiment, heart rate, systolic blood pressure (SBP), diastolic blood pressure (DBP), and mean arterial pressure (MAP) were recorded using a direct measurement method through the carotid artery with a Biopac MP150 (Biopac Data Acquisition System). The purpose of detecting hemodynamic changes was to observe the heart condition of each group of experimental rats before, during and after the experiment. Electrocardiography leads were placed on limbs. After median sternotomy, a 4-0 silk suture was passed around the proximal part of the left anterior descending coronary artery. The ends of the silk suture were threaded through a small vinyl tube to form a snare. The body temperature was monitored using a rectal thermometer and maintained at $37^{\circ} \mathrm{C}$ with heating pads throughout the experiments.

After achieving hemodynamic stability for $20 \mathrm{~min}$, the rats were divided randomly into four groups. Group 1 rats (Sham) underwent the same surgical procedures without any pretreatment, $\mathrm{CAO}$ or reperfusion. Group 2 rats $(\mathrm{CAO})$ did not receive any pretreatment. Group 3 rats (EXC) underwent 4 weeks of swimming training intervention prior to surgery. In group 4 rats (IPC), IPC was induced via two 10-min episodes of CAO. The two episodes of CAO were followed by $10 \mathrm{~min}$ of reperfusion. At $10 \mathrm{~min}$ after the previously mentioned treatments, a 40 -min CAO was induced in the rats in groups 2, 3 and 4 by pulling the snare around the left anterior descending coronary artery. Successful occlusion was verified by observing the development of ST segment elevation and changes in the QRS complex on the electrocardiogram and cyanotic changes in the myocardium in the occluded area. After $40 \mathrm{~min}$ of CAO, the snare was released for reperfusion for $3 \mathrm{~h}$. Reperfusion was confirmed by refilling of the coronary artery and visualizing a 
reactive hyperemic response. Arterial pressure, heart rate and electrocardiography were recorded simultaneously and continuously throughout the experiment. The grouping flowchart is shown in Fig. 1. After the operation, rats were euthanized by exsanguination. Blood specimens were collected from the carotid artery and serum separated after centrifugation $\left(2,000 \mathrm{x} \mathrm{g}\right.$ at $4^{\circ} \mathrm{C}$ for $\left.20 \mathrm{~min}\right)$ for biochemical research.

Determination of the area at risk (AAR) and MI size. The dyeing methods of Zhao et al (43) were followed. After the experiment was completed, heparin (1,000 U) was injected intravenously. Subsequently, the heart was resected and the previous MI site was re-ligated. Next, 1\% Evans blue dye (MilliporeSigma) was perfused into the ascending aorta. After perfusion was completed, five transverse sections were made through the left ventricle and interventricular septum. The sections were immersed in $1 \%$ triphenyl tetrazolium chloride solution and heated in a $37^{\circ} \mathrm{C}$ thermostatic water bath for $20 \mathrm{~min}$. After heating, the sections were weighed, and $10 \%$ formalin solution was added to fix the sections at room temperature for $24 \mathrm{~h}$. The colors of blue, pale and red respectively represented the normal, infarcted and ischemic tissue. The total weight of the AAR and MI were calculated and the sum was taken. AAR is defined as the myocardial tissue within the vascular territory that is distal to the culprit lesion of the infarct-related artery. AAR is the percentage of the weight of the red area divided by the weight of the left ventricle; MI is the percentage of the weight of the white area divided by the red area (44).

Biochemical analysis of cardiac function. Blood was collected from rats in each group after the experiment was completed. The levels of troponin I, lactate dehydrogenase (LDH) and creatine phosphokinase (CPK) were subsequently measured. CPK and LDH activities were determined according to standard methods using diagnostic kits from BioSystems S.A. Assessment of serum troponin I was carried out via enzyme-linked immunosorbent assay (ELISA) using a commercial kit purchased from DRG International, Inc. The concentration of Troponin-I, LDH and CPK in the blood is increased following myocardial damage, such as acute myocardial infarction, shock, hypoxia or acute coronary artery disease. Therefore, the aforementioned factors can be used as the clinical diagnosis of myocardial infarction and evaluation (45).

Histological examination of the heart. At the end of the experiment, the hearts from four rats in each group were harvested. Part of the heart was fixed using $10 \%$ paraformaldehyde at room temperature for $24 \mathrm{~h}$, dehydrated, embedded in paraffin, cut into $4-\mu \mathrm{m}$ sections and mounted on glass slides. The sections were then deparaffinized using xylene at room temperature for $10 \mathrm{~min}$, and counterstained using hematoxylin and eosin $(\mathrm{H} \& \mathrm{E})$ at room temperature for $7 \mathrm{~min}$. Finally, the samples were analyzed using an inverted light microscope (CKX53; Olympus Corporation) at x400 magnification. The severity of myocardial injury was determined using a morphological scoring system as follows: 0 , no damage; 1 , interstitial edema and focal necrosis; 2, diffuse myocardial cell swelling and necrosis; 3 , necrosis with contraction bands and neutrophil infiltrate; and 4, widespread necrosis with contraction bands,

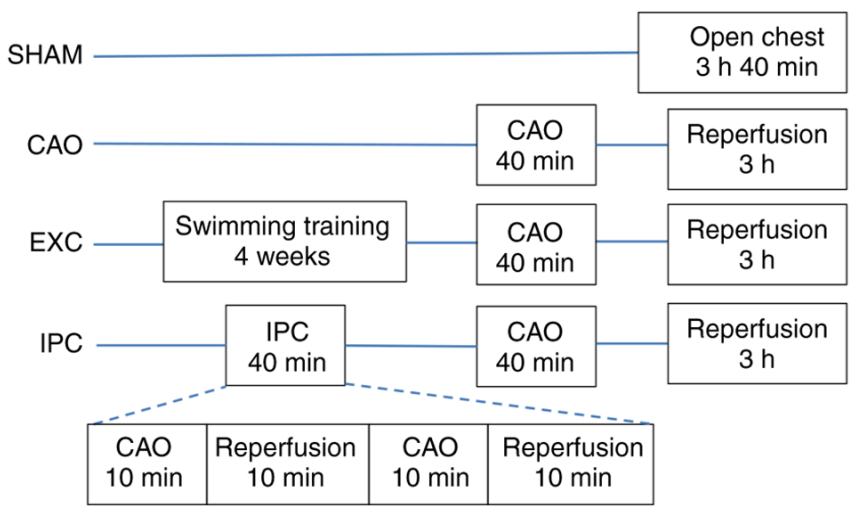

Figure 1. The experimental protocol used in the present study. With the exception of the SHAM group, all rats underwent a 40-min CAO and 3-h reperfusion after the different treatments. During the treatment period, the SHAM group did not receive any pretreatments. The EXC group first underwent 4 weeks of swimming training before the experiment. The IPC group received ischemic preconditioning by undergoing two 10 -min episodes of CAO and 10-min reperfusion. CAO, coronary artery occlusion; EXC, swimming training; IPC, ischemic preconditioning.

neutrophil infiltrate and hemorrhage. The evaluation of the myocardial damages based on the HE staining was the average of the scores from two separate examiners (46). To make comparisons between groups, the mean score and standard deviation of each group was calculated.

TUNEL staining analysis of the heart. Briefly, when the experiments were completed, the hearts were cut into $4-\mu \mathrm{m}$ sections and fixed in acetone at room temperature for $24 \mathrm{~h}$. Then, the samples were moved into a solution containing terminal deoxynucleotidyl transferase and detection buffer (Roche Diagnostics $\mathrm{GmbH}$ ), conjugated with horseradish peroxidase, and incubated at $37^{\circ} \mathrm{C}$ for $60 \mathrm{~min}$. A diamino-benzidine-chromogen (Boehringer) was used. Several further steps were introduced to obtain the end value of the number of TUNEL-positive nuclei, including the samples were analyzed using an inverted light microscope (CKX53; Olympus Corporation) at x400 magnification, then selecting an area randomly, counting the nuclei in that area, and converting the value to a percentage by dividing it by the total number of the cell nuclei.

Western blot analysis. Briefly, when the experiments were completed, the hearts of four rats from each group were moved into the tissue protein extraction reagent (T-PER; Thermo Fisher Scientific, Inc.) at $4^{\circ} \mathrm{C}$ for homogenization; the myocardial cell lysate was prepared in cold lysis buffer [25 mM Tris- $\mathrm{HCl}$ (pH 7.6), $150 \mathrm{mM} \mathrm{NaCl,} \mathrm{1 \%} \mathrm{NP-40,}$ $1 \%$ sodium deoxycholate, $0.1 \%$ SDS]. Samples were centrifuged at $10,000 \mathrm{x} \mathrm{g}$ at $4^{\circ} \mathrm{C}$ for $10 \mathrm{~min}$, and a modified Bradford assay which compared with the conventional Bradford method was used to determine protein concentrations. Notably, the characteristics are stable, the measurement speed is fast, the sensitivity is high and the error rate is small. A total of $60 \mu \mathrm{g}$ of protein were loaded and separated using 15\% SDS-PAGE and then transferred to a nitrocellulose membrane. After blocking with 5\% non-fat dry milk in Tris-buffered saline containing $0.1 \%$ Tween-20 (TBST) at $37^{\circ} \mathrm{C}$ for $30 \mathrm{~min}$, the membranes 
were incubated with anti-caspase-3 (cat. no. IMG-144A; Imgenex), anti-TNF- $\alpha$ (cat. no. sc-52746; Santa Cruz Biotechnology) or anti-Bcl-2 antibodies (cat. no. 633502; BioLegend; all 1:1,000) in 5\% non-fat dry milk at $4^{\circ} \mathrm{C}$ for $24 \mathrm{~h}$. The membranes were then incubated in $5 \%$ non-fat dry milk

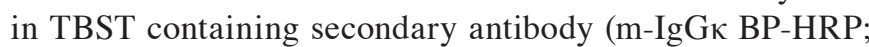
cat. no. sc-516102; Santa Cruz Biotechnology; 1:1,000) conjugated to horseradish peroxidase. To visualize the peroxidase activity, an enhanced chemiluminescence substrate system was used, followed by exposing the membranes to hyperfilms. $\beta$-actin (cat. no. 643802; BioLegend; 1:1,000) was used at room temperature for $2 \mathrm{~h}$ as a loading control. Image J version 1.6 (National Institutes of Health) was used for densitometry analysis, and each gel was normalized against the background density.

Capillary density measurements in tissue sections. To visualize the capillaries in the myocardium, endothelial cells were stained with CD31, often used as a biological marker to represent the capillary vessels in the myocardium. Angiogenesis was quantitatively assessed based on CD31-positive capillary vessels for the determination of capillary density. For immunostaining, a rabbit anti-rat CD31 antibody (cat. no. sc-376764; Santa Cruz Biotechnology; 1:100) was used at room temperature for $15 \mathrm{~min}$. Staining was visualized by reaction with DAB (MilliporeSigma; 1:20). Capillaries were visualized in the myocardium as a brown precipitate, identified as having a diameter $<20 \mu \mathrm{m}$ and a layer of endothelial cells without smooth muscle cells. Computer-assisted morphometry was performed using Image Pro Plus version 5.0 (Media Cybernetics, Inc).

Statistical analysis. Data are presented as the mean \pm standard deviation, and statistical analysis was performed using SPSS 20.0 (IBM Corp.). Hemodynamic variables were analyzed using a two-way repeated measures ANOVA. Otherwise, data were analyzed using a one-way ANOVA and a Bonferroni post hoc multiple comparisons test. The ordinal values of the myocardial injury scores were analyzed using a Mann-Whitney $\mathrm{U}$ test. $\mathrm{P}<0.05$ was considered to indicate a statistically significant difference.

\section{Results}

Comparison of mortality rates amongst the four groups. A total of 42 rats were used in the present study. Of those 42 rats, 1 rat in the CAO group died from heart failure, which was defined as a progressive decrease of the systolic arterial pressure to $<50 \mathrm{mmHg}$ with global left ventricular dilatation and poor contraction; and 1 rat in the IPC group developed ventricular fibrillation and died. These two rats were excluded from the study. No statistically significant difference was observed amongst the four groups in terms of mortality rate $(\mathrm{P}=0.591)$.

Comparison of changes in hemodynamic variables during the experiments amongst the four groups. No significant difference was found amongst the four groups in terms of mean arterial pressure and heart rate, at baseline and throughout the experiments. In addition, the changes in hemodynamic variables did not reach a level of statistical significance during the experiments in the four groups (Table I).
Comparison of $A A R$ and $M I$ size amongst the CAO, EXC and $I P C$ groups. When the experiments were completed, six rats from each group were randomly selected to collect cardiac tissues for AAR and MI size analysis. The AAR of the left ventricular infarct area is shown in Fig. 2A. The MI size, expressed as a percentage of AAR, is shown in Fig. 2B. The results demonstrated that there was no statistically significant difference in AAR amongst the three groups $(50.44 \pm 1.75 \%$ in $\mathrm{CAO}$ vs. $49.90 \pm 1.62 \%$ in EXC and $49.29 \pm 0.88 \%$ in IPC; $\mathrm{P}>0.05$ ), while the MI size was significantly decreased in the EXC and IPC experimental groups compared with the CAO group $(20.27 \pm 0.88 \%$ in EXC and $19.37 \pm 0.95 \%$ in IPC vs. $28.15 \pm 1.54 \%$ in $\mathrm{CAO} ; \mathrm{P}<0.001)$.

Intervention with EXC and IPC significantly reduces the serum concentrations of troponin I, LDH and CPK after myocardial I/R. When the experiments were completed, six rats from each group were randomly selected to collect blood samples for biochemical analysis of cardiac function. CAO group rats, compared with Sham group rats, exhibited significantly increased serum levels of troponin I $(298.08 \pm 173.09 \mathrm{ng} / \mathrm{ml}$ vs. $0.68 \pm 0.47 \mathrm{ng} / \mathrm{ml}$, respectively; $\mathrm{P}<0.05$; Fig. 3A), LDH $(4,606.17 \pm 1,057.12 \mathrm{U} / 1$ vs. $259.83 \pm 127.48 \mathrm{U} / 1$, respectively; $\mathrm{P}<0.001$, Fig. $3 \mathrm{~B})$ and $\mathrm{CPK}$ $(8,531.33 \pm 591.00 \mathrm{U} / 1$ vs. $577.50 \pm 19.40 \mathrm{U} / 1$, respectively; $\mathrm{P}<0.001$, Fig. 3C). The EXC and IPC groups exhibited significantly less prominent increases in the serum levels of troponin I $(41.56 \pm 10.44$ and $41.31 \pm 9.23 \mathrm{ng} / \mathrm{ml}$, respectively, vs. the CAO group; P<0.05; Fig. 3A), LDH $(1,496.33 \pm 292.03$ and $1,351.83 \pm 265.11 \mathrm{IU} / 1$, respectively, vs. the CAO group;

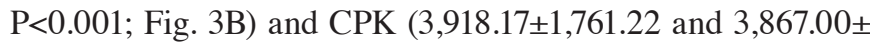
$755.85 \mathrm{U} / 1$, respectively, vs. the $\mathrm{CAO}$ group; $\mathrm{P}<0.01$; Fig. $3 \mathrm{C}$ ). No significant differences between the EXC and IPC groups were observed $(\mathrm{P}>0.05)$.

EXC and IPC interventions significantly reduces MIRI. At the end of the experiments, four rats from each group were randomly selected, and part of their hearts was sent for histological examination in order to identify cardiac injury. The myocardium in the left ventricle of the rats in the Sham group appeared normal (Fig. 4A); however, the myocardium of rats in the CAO group exhibited interstitial edema, myocardial cell swelling and disruption of myocardial fibers. The myocardial injury scores of the rats in the CAO group were significantly higher compared with those of the rats in the Sham group $(\mathrm{P}<0.001$; Fig. 4B). However, EXC and IPC significantly reduced the extent of histological damage, and the myocardial injury scores of the rats in the EXC and IPC groups were significantly decreased compared with those in the CAO group $(\mathrm{P}<0.001)$.

EXC and IPC interventions significantly reduces the number of apoptotic cardiomyocytes after myocardial I/R. TUNEL staining is a sensitive method commonly used for detecting apoptosis (47). At the end of the experiment, four rats from each group were randomly selected, and their hearts were subjected to TUNEL staining, which was used to locate DNA fragmentation in the nuclei of apoptotic cardiomyocytes appearing as a dark brown reaction product. Of note, only a small portion of the hearts of the rats in the Sham group 


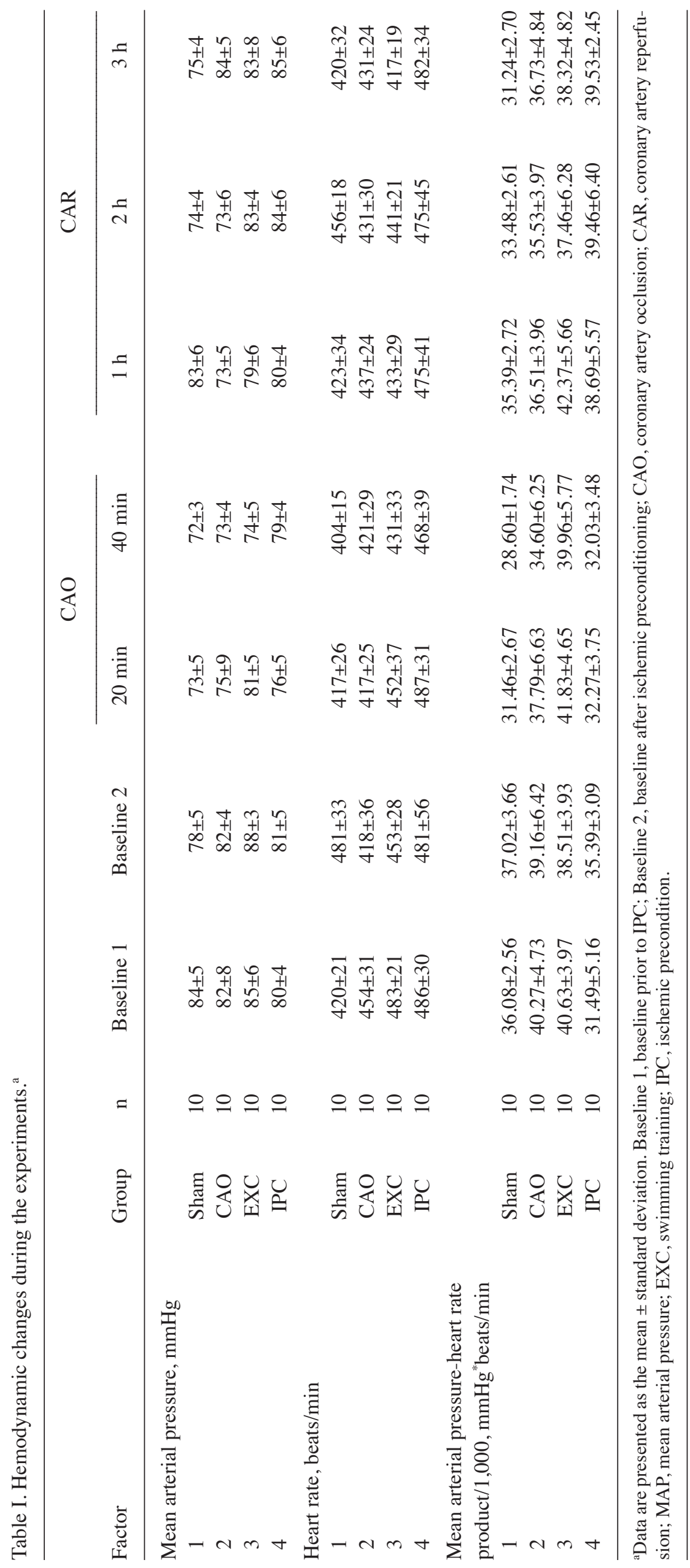



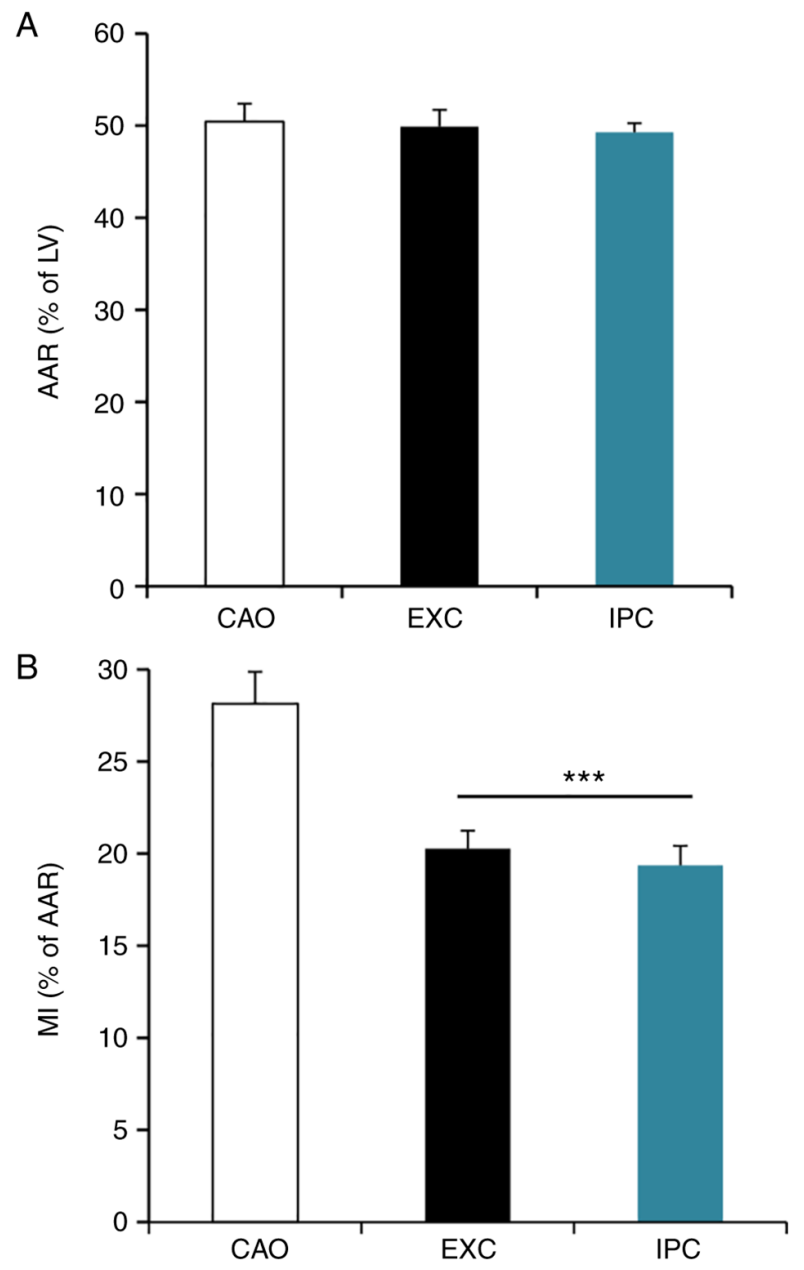

Figure 2. AAR and MI size. (A) AAR, as a percentage of the total LV area. (B) Size of MI, expressed as a percentage of the AAR. $n=6 .{ }^{* * *} \mathrm{P}<0.001$. CAO, coronary artery occlusion; EXC, swimming training; IPC, ischemic preconditioning; AAR, analysis of the area at risk; MI, myocardial infarction; $\mathrm{LV}$, left ventricle.

exhibited TUNEL-stained nuclei (Fig. 5A). With regard to the rats in the $\mathrm{CAO}$ group, heart samples were also found to exhibit TUNEL staining, which was induced by myocardial I/R. In the EXC and IPC groups, dark brown staining was observed in the heart samples in the form of scattered nuclei. There was a significant increase in the percentage of the TUNEL-positive nuclei against the total nuclei in the hearts of the rats from the CAO group compared with the Sham group ( $34.4 \pm 5.5 \%$ vs. $2.3 \pm 0.7 \%$, respectively; $\mathrm{P}<0.001$; Fig. $5 \mathrm{~B}$ ), and the corresponding percentages in the EXC and IPC groups were decreased significantly $(19.7 \pm 1.2$ and $19.0 \pm 1.5 \%$, respectively, vs. the CAO group; $\mathrm{P}<0.05$; Fig. 5B). No significant difference in the numbers of TUNEL-positive nuclei between the EXC and IPC groups was observed (Fig. 5B).

EXC and IPC interventions significantly reduces the levels of TNF- $\alpha$ and activated caspase-3, and increases the levels of Bcl-2 in cardiomyocytes. TNFs are, a family of cellular signaling proteins that are involved in systemic inflammation, and are some of the most critical pro-inflammatory cytokines (48). Activated caspase-3 is a universal effector of apoptosis (49), and $\mathrm{Bcl}-2$ is an important gene family that
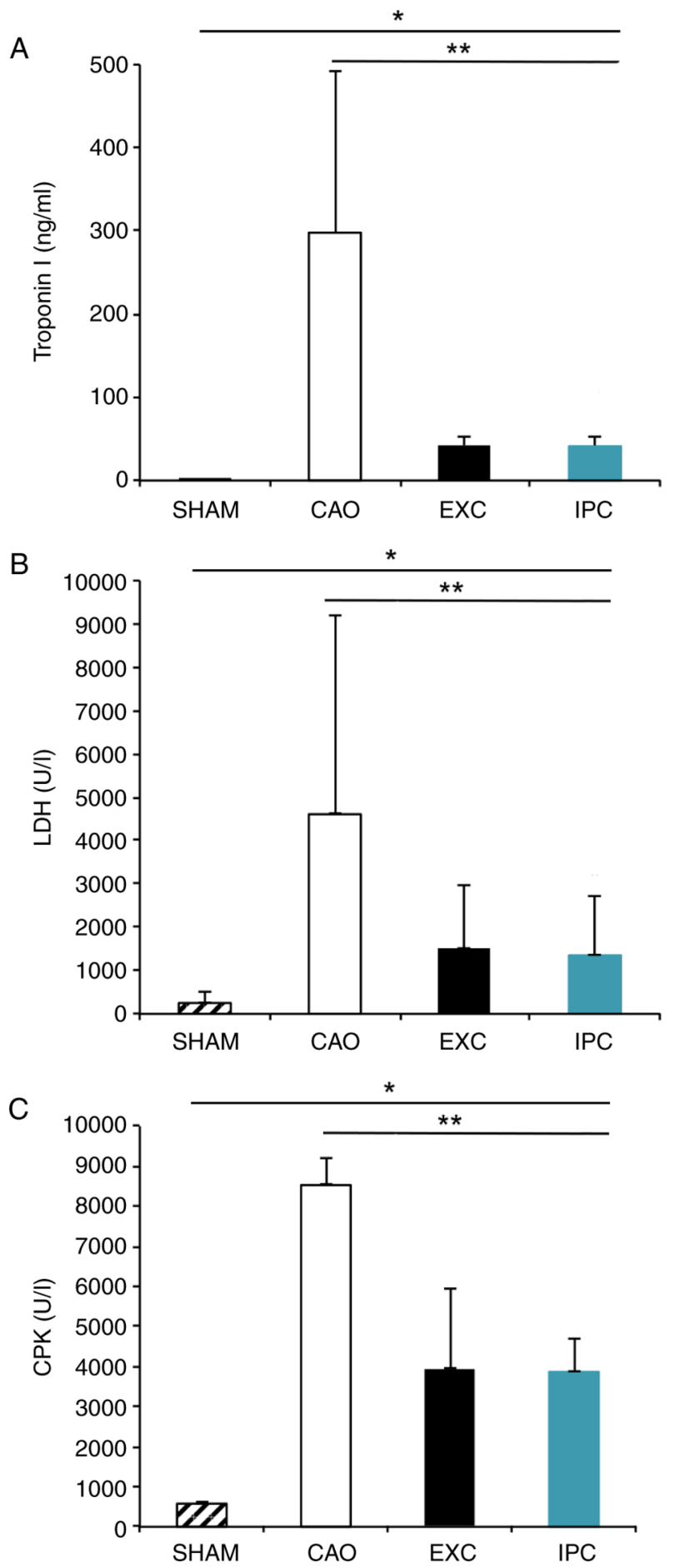

Figure 3. Biochemical analysis of cardiac function. (A) Troponin I, (B) LDH and (C) CPK levels. $\mathrm{n}=6 .{ }^{*} \mathrm{P}<0.05 ;{ }^{* *} \mathrm{P}<0.01$. LDH, lactic dehydrogenase; $\mathrm{CPK}$, creatine phosphokinase; CAO, coronary artery occlusion; EXC, swimming training; IPC, ischemic preconditioning.

controls the primary apoptotic pathway (49). To measure the levels of TNF- $\alpha$, activated caspase- 3 and Bcl-2, four rats from each group were randomly selected and western blot analysis on their heart samples was conducted at the end of the experiments. Compared with the Sham group, myocardial I/R significantly increased the TNF- $\alpha$ levels in the hearts of the rats in the CAO group $(\mathrm{P}<0.001$; lane 2, Fig. 6A). The EXC and IPC groups exhibited a significantly less prominent increase 
A

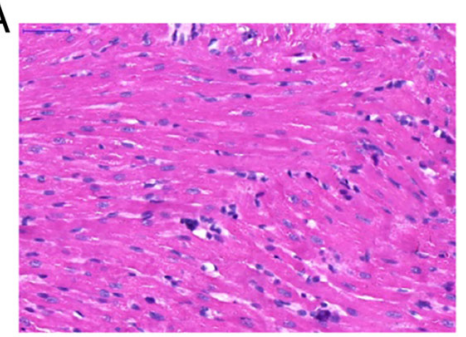

SHAM

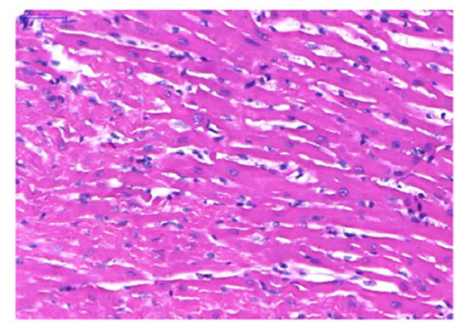

EXC
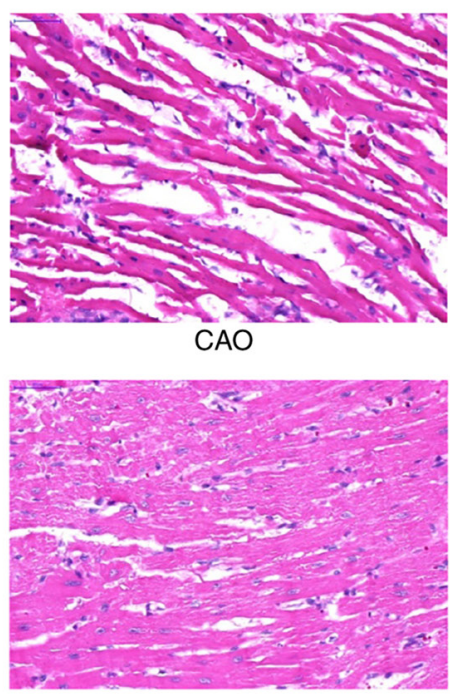

IPC
B

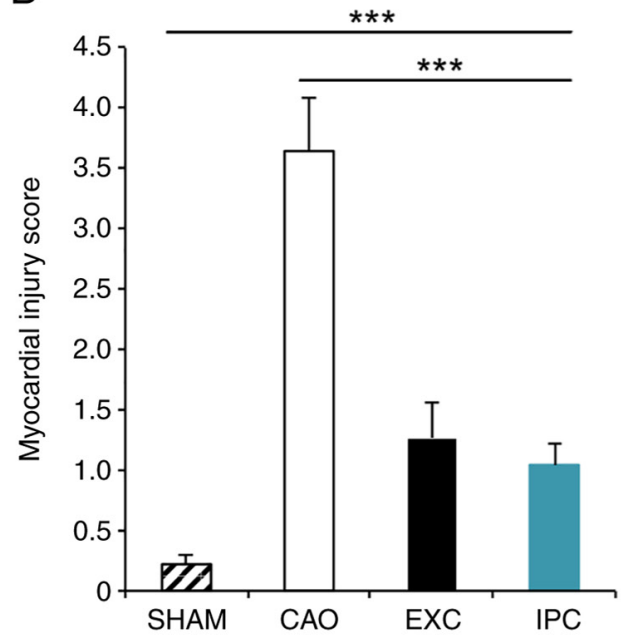

Figure 4. Histological examination of cardiac injury. (A) Representative images of hematoxylin and eosin staining of the heart sections. Magnification, x400. The myocardial tissue morphology of rats in the SHAM group appeared normal. Interstitial edema, myocardial cell swelling and the disruption of myocardial fibers of the rats in the CAO group is shown. (B) Histological injury scores of the myocardial tissue. $\mathrm{n}=4 .{ }^{* * * *} \mathrm{P}<0.001$. CAO, coronary artery occlusion; EXC, swimming training; IPC, ischemic preconditioning.

A

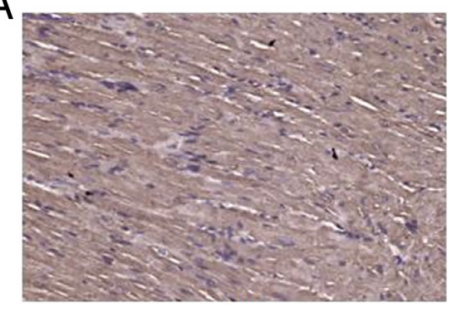

SHAM

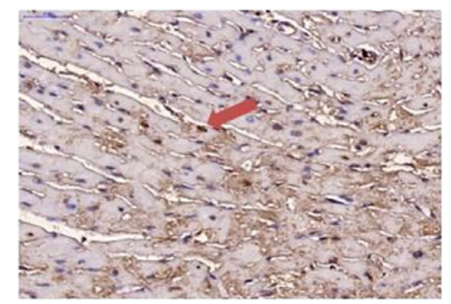

EXC

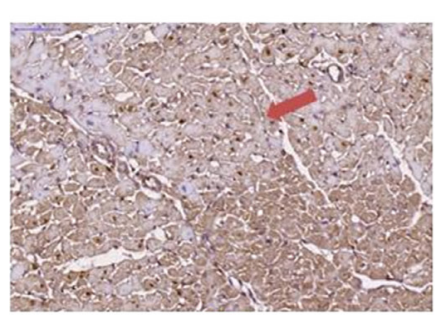

CAO

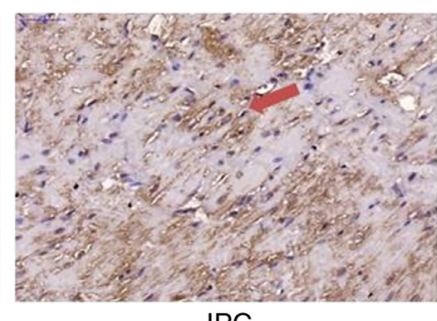

IPC
B

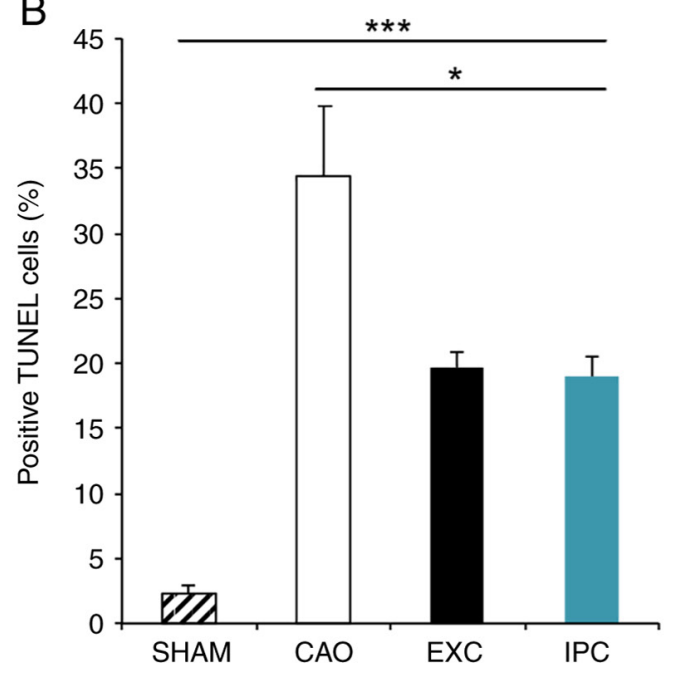

Figure 5. Analysis of apoptosis in the heart. (A) Representative images of TUNEL staining. Magnification, x400. Dark brown staining (red arrow) indicates TUNEL-positive nuclei. (B) Percentage of TUNEL-positive nuclei in each group. $\mathrm{n}=4 .{ }^{*} \mathrm{P}<0.05 ;{ }^{* * * *} \mathrm{P}<0.001$. CAO, coronary artery occlusion; EXC, swimming training; IPC, ischemic preconditioning.

in TNF- $\alpha$ levels in the hearts subjected to myocardial $\mathrm{I} / \mathrm{R}$ $(\mathrm{P}<0.001$ vs. CAO group; lanes 3 and 4, Fig. 6A). There was no significant difference in TNF- $\alpha$ expression between the EXC and IPC groups (Fig. 6A). Caspase-3 is cleaved to an active p17 subunit $(17 \mathrm{kDa})$ when apoptosis is induced. According to the results of western blot analysis, which showed a significant increase in the activated caspase- 3 band, it was inferred that myocardial I/R could increase the levels of activated caspase-3 in the hearts $(\mathrm{P}<0.001$ vs. Sham group; lane 2, Fig. 6B); conversely, the increase in activated caspase- 3 was significantly inhibited in the EXC and IPC groups ( $\mathrm{P}<0.001$ vs. CAO group; lanes 3 and 4, Fig. 6B). No significant difference in the activated caspase-3 expression between the EXC and IPC groups was observed (Fig. 6B). Compared with the Sham group, CAO group hearts exhibited a significant reduction in Bcl-2 levels $(\mathrm{P}<0.001$ vs. Sham group; lane 2, Fig. 6C), while this decrease in Bcl-2 levels was significantly inhibited in the EXC and IPC groups ( $\mathrm{P}<0.001$ vs. CAO group; lanes 3 and 4, Fig. 6C). No significant difference in the Bcl-2 expression levels between the EXC and IPC groups was observed (Fig. 6C).

EXC significantly increases the density of myocardial blood vessels. At the end of the experiments, four rats from each group were randomly selected, and part of their hearts were used for CD31 staining analysis in order to identify the density of myocardial blood vessels. Compared with the Sham, 


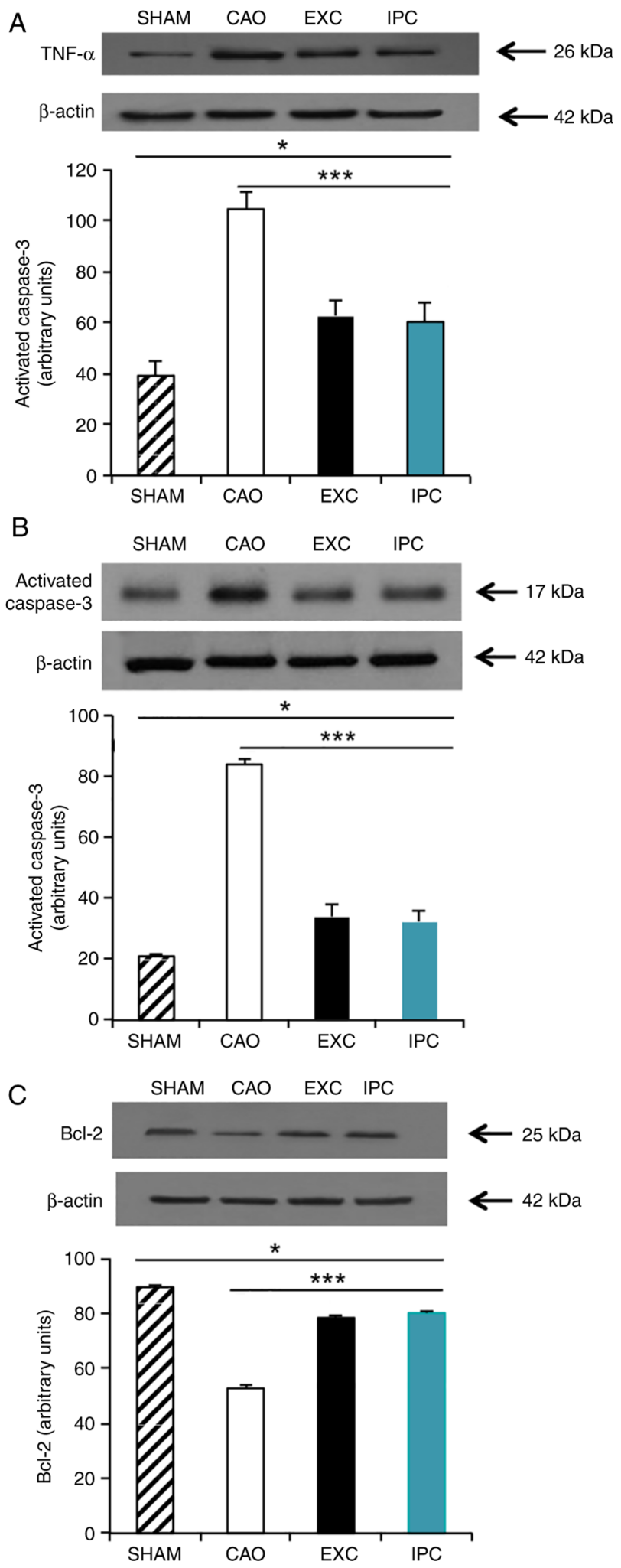

Figure 6. Determining the levels of TNF- $\alpha$, activated caspase-3 and Bcl-2 in the heart. (A) TNF- $\alpha$, (B) activated caspase-3 and (C) Bcl-2 assays. Representative western blots of TNF- $\alpha$, activated caspase-3 and Bcl-2 expression are shown. The density of TNF- $\alpha$, activated caspase-3, and Bcl-2 were analyzed. $\mathrm{n}=4 .{ }^{*} \mathrm{P}<0.05 ;{ }^{* * *} \mathrm{P}<0.001$. CAO, coronary artery occlusion EXC, swimming training; IPC, ischemic preconditioning.

CAO and IPC groups, the EXC group exhibited a significant increase in the density of myocardial blood vessels $(\mathrm{P}<0.001$ vs. SHAM, CAO and IPC groups; Fig. 7).

\section{Discussion}

In the present study, it was demonstrated that swimming training could significantly decrease myocardial injury, MI size, serum concentrations of MI markers (troponin I, CPK and $\mathrm{LDH}$ ) and cardiomyocyte apoptosis following a myocardial $I / R$, and the myocardial protective effects were even comparable to those of the commonly used method of IPC.

The intense and sustained changes of myocardial injury that occur during the myocardial ischemic period lay the foundation for the reperfusion injury that follows. This type of $\mathrm{I} / \mathrm{R}$ injury has been proven to be an extension of ischemic injury, which further exacerbates irreversible myocardial injury $(44,46)$. Therefore, strategies for preventing reperfusion injury are the important aspect of treatment of related heart diseases. Previous studies have proven that IPC can significantly decrease MI size, DNA laddering, the number of TUNEL-stained nuclei and cardiomyocyte apoptosis to exert cardioprotective effects $(50,51)$.

It has been demonstrated that the cardioprotective effects of IPC can be exerted in two temporal windows. The first is active within minutes to hours after the conditioning stress; the second, known as 'second window of protection', becomes active 1-3 days later $(52,53)$. The mechanisms underlying training-induced cardioprotection resemble those elicited by IPC, whereby short ischemic episodes prior to a major ischemic insult trigger endogenous cardioprotective mechanisms. Training may induce IPC by emulating minor local ischemic episodes, with ischemia occurring as short periods of time during which the supply of blood and oxygen to tissues is limited with respect to the tissue requirements (54).

The experimental results of the present study revealed that MI size was significantly decreased after myocardial $I / R$ in rats that underwent swimming training. There was no significant difference in AAR among the three groups (groups 2-4) and no significant hemodynamic changes were observed during the surgical procedure. Therefore, reduced MI size could not be attributed to differences in surgical technique or hemodynamic changes.

Intermittent hypoxia is broadly defined as repeated episodes of hypoxia interspersed with episodes of normoxia. The definition of intermittent hypoxia varies widely in terms of cycle length, number of hypoxic episodes per day and the number of days of exposure. Nevertheless, it has been confirmed that repeated incidents of ischemia and hypoxia may lead to physiological changes and are considered as one of the key factors involved in cardiovascular diseases, general inflammation and heart disease $(55,56)$.

Intermittent hypoxia primarily affects the cardiac structure and function via oxidative damage caused by free radicals (57). Myocardial I/R disrupts the mitochondrial respiratory chain and is accompanied by ATP depletion, resulting in the accumulation of mitochondrial ROS (51). The effects of IPC are mediated through activating $\mathrm{K}_{\text {ATP }}$ channels in the mitochondria. Once activated, the progress of phosphorylation in mitochondria is accelerated, which results in a reduction in ATP consumption in mitochondria, i.e., a reduction in the metabolic rate in cells (58). ROS levels increase during exercise; however, mounting epidemiological data have proven that exercise decreases the incidence of 
A

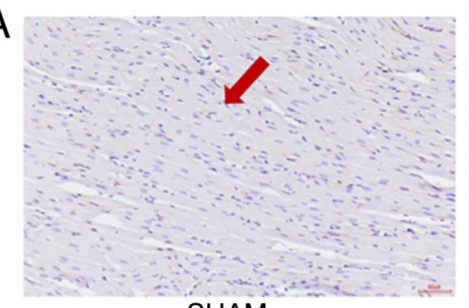

SHAM

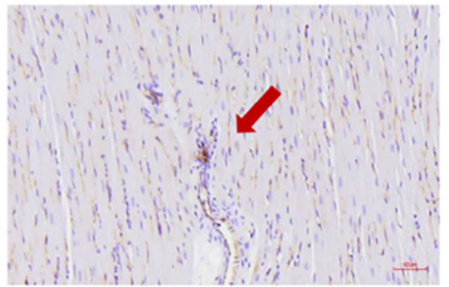

EXC

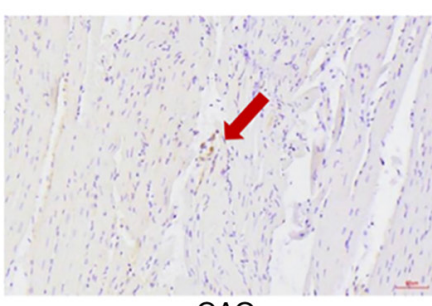

CAO

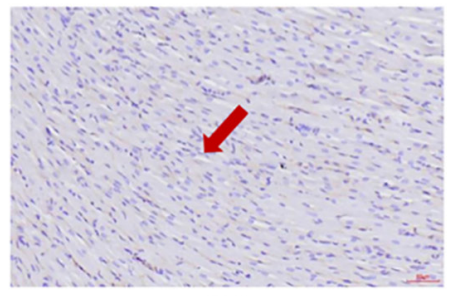

IPC
B

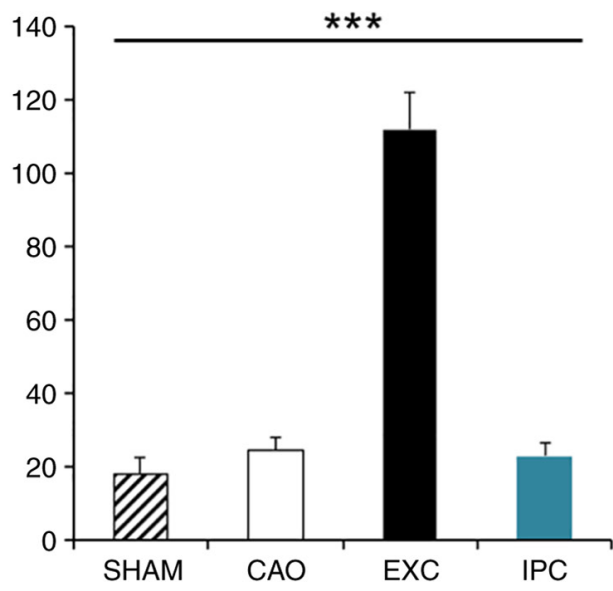

Figure 7. Myocardial tissue angiogenesis. (A) Representative images of CD31 staining. Magnification, x400. Arrows indicate muscle actin-positive micro vessels. (B) Quantitative morphometric analysis of arteriole density. $\mathrm{n}=4{ }^{* * * *} \mathrm{P}<0.001$. CAO, coronary artery occlusion; EXC, swimming training; IPC, ischemic preconditioning.

oxidative stress-associated diseases owing to exercise-induced adaptation $(59,60)$. Exercise training can protect cardiac subsarcolemmal and intermyofibrillar mitochondria, enabling them to adapt to transient hypoxia and decreasing ROS production, increasing their ability to tolerate high calcium levels, and preventing oxidative damage caused by myocardial I/R to achieve cardioprotection $(61,62)$. In addition, mitochondria contain an antioxidant enzyme known as Mn superoxide dismutase (MnSOD) that can decrease intracellular oxidative stress (63). The cytoplasm also possesses a $\mathrm{Cu} / \mathrm{ZnSOD}$ that has a function similar to MnSOD (64). Research indicates that IPC can exert protective effects through the induction of MnSOD. In addition, the levels of MnSOD and $\mathrm{Cu} / \mathrm{ZnSOD}$ were found to be increased in rat cardiomyocytes after exercise training, which inhibited apoptosis $(65,66)$. Therefore, it may be hypothesized that myocardial antioxidant effects induced by exercise can decrease myocardial injury and cellular damage, thereby reducing MI size.

When cardiomyocytes are exposed to ischemia or hypoxia, the mitochondrial matrix shrinks, leading to an enlargement of the intermembrane space and resulting in a disorientation of cardiomyocytes and disruption of the myocardial structure, and a release of endocardial substances (67). In addition, ischemia in the myocardium can cause the membrane potential of mitochondria to dissipate, leading to an increase in the permeability and an opening in mitochondrial permeability transition pore (mPTP), resulting in a release of apoptosis-inducing factors from mitochondria (67). Therefore, the evaluation of cardiomyocyte injury could be performed by determining the plasma levels of specific and sensitive biomarkers, such as troponin I, CPK and LDH (68-70). It has been found that IPC, by activating protein kinase $C$, can open $\mathrm{K}_{\mathrm{ATP}}$ channels, reduce the release of myocardial enzymes by reducing the consumption of ATP, and create an inflow of potassium ions and other ions, which may help the myocardium reach a balance in osmotic pressure and potential equilibrium, so as to mitigate myocardial injury (71). Theoretically, the cardioprotective effects of exercise may be attributed to the fact that exercise training induces a mitochondrial phenotype, including increases in the protein levels of primary antioxidant enzymes in both subsarcolemmal and interfibrillar mitochondria, attenuation of ROS-induced cytochrome $c$ release, and reduced maximal rates of mPTP opening (72,73). Furthermore, the ratio of blood vessels/muscle fibers increases in healthy hearts after exercise intervention. In addition, exercise training in advance can also increase angiogenesis after MI $(74,75)$. Similar results were obtained in the present study, which showed that swimming intervention increased angiogenesis in the heart. The results of the present study showed that cardiomyocytes released troponin I, LDH and CPK into the blood after I/R. Therefore, these three enzymes were found to be significantly elevated in the CAO group. On the other hand, there were significantly lower levels of the aforementioned three enzymes in the EXC and IPC groups compared with those in the CAO group. Therefore, it can be deduced that exercise training decreased I/R-induced damage by exerting cardioprotective effects through protecting myocardial mitochondria, increasing myocardial vascularization and maintaining cardiomyocyte integrity, thereby decreasing the release of the aforementioned enzymes. In addition, examination of HE-stained myocardial sections revealed that the myocardium exhibited deformation and expansion, and the muscle fibers were arranged in a disorderly manner after myocardial I/R, and these changes were significantly reduced following treatment intervention with EXC and IPC.

The free radicals produced during myocardial I/R can activate NF- $\kappa$ B. Subsequently, TNF- $\alpha$, which induces the transcription of $\mathrm{NF}-\kappa \mathrm{B}$, can directly damage vascular endothelial cells and cardiomyocytes (76). Functionally, TNF- $\alpha$ could trigger cellular responses via interacting with its transmembrane receptors, such as TNF receptor 1 (TNFR1) (77). Upon activation by TNF- $\alpha$, TNFR1 can activate the death induction signal mediated by TNF receptor-associated death domain and Fas-associated death domain in order to activate caspase-3, -6 and -8 , and reduce the production of the anti-apoptotic protein Bcl-2, eventually causing apoptosis $(78,79)$. 
$\mathrm{NF}-\kappa \mathrm{B}$ is a family of inducible transcription factors that serve a variety of evolutionarily conserved roles in the immune system. Cytokines belonging to the TNF family induce rapid transcription of genes regulating inflammation, cell survival, proliferation and differentiation, primarily through activation of the $\mathrm{NF}-\kappa \mathrm{B}$ pathway (80). IPC can impose mild oxidative stress on cells, which can activate NF- $\mathrm{B}$ and induce $\mathrm{Bcl}-2$, which in-turn reduce the extent of cardiomyocyte damage and apoptosis during the subsequent I/R process (81). Exercise can trigger short-term inflammation, alongside an increase in white blood cells, oxidative stress and the levels of C-reactive protein (CRP). Regular exercise reduces CRP, IL- 6 and TNF- $\alpha$ levels, and also increases the levels of anti-inflammatory factors, such as IL-4 and IL-10 (82). The results of the present study demonstrated that the concentration of TNF- $\alpha$ in the myocardial cells of both EXC and IPC group rats decreased significantly, indicating that exercise reduced the concentration of TNF- $\alpha$ and reduced the inflammatory and apoptotic responses to achieve cardioprotective effects.

Apoptosis and necrosis are two types of cell death induced by myocardial I/R. Apoptosis-related genes, such as those of the Bcl-2 or caspase families, are known components of the signaling pathway controlling apoptosis. The caspase family is a protease system that directly causes apoptosis. Activation of both the extrinsic and the intrinsic apoptotic pathway results in cleavage of caspase-3, which activates the execution phase of apoptosis (82). Bcl-2 enhances proton release from the mitochondria and exerts a regulatory effect on the opening of the mPTP, and therefore has an anti-apoptotic effect (83). Caspase-3 is activated by intracytoplasmic release of mitochondrial proteins, such as cytochrome $c$ and apoptosis-inducing factor, which is restrained by Bcl-2 and Bcl-xL upstream of caspase. Furthermore, the expression of antiapoptotic genes, such as Bcl-2 or Bcl-xL, is activated by the suppression of the transcription factor $N F-\kappa B$, which restrains apoptosis (81). It was previously demonstrated that IPC could attenuate caspase-3 activation and increase $\mathrm{Bcl}-2$ performance $(84,85)$. These findings suggest that prevention of caspase activation may contribute to myocardial protection.

The heat shock response is a common cellular reaction to external stimuli, such as ischemia, hypoxia, acidosis, oxidative stress, protein degradation, increased intracellular calcium and energy depletion; therefore, IPC can also activate the release of heat shock proteins (HSPs) $(86,87)$. Exercise also increases the expression of cardiac HSPs, as a variety of stressors associated with exercise, including heat stress and hypoxia, reduced intracellular $\mathrm{pH}$, ROS and reactive nitrogen species production, depletion of glucose and glycogen stores, increase in cytosolic calcium levels and cardiomyocyte stretching, can all contribute to HSP elevation in cardiac muscle (88). The protective effects of HSPs on cardiomyocytes include maintenance of myocardial calcium ion concentration and a decrease in the release of pro-inflammatory factors. HSPs can also regulate ATP synthesis in the mitochondria and affect signal transduction through the MAPK/JNK pathway to inhibit apoptosis and increase the anti-apoptotic capacity in cardiomyocytes (89-91). Certain researchers even consider HSPs, in addition to Bcl-2, as a type of anti-apoptosis protein $(90,92,93)$. The present study found that, in addition to a smaller infarct size in the EXC and the IPC groups, the extent of apoptosis and the expression of caspase- 3 in cardiomyocytes decreased considerably, while the expression of Bcl-2 in cardiomyocytes in both groups increased substantially. By inference, this may result from an increase in HSP levels after swimming training and preconditioning of the rats, which strengthens the effect of cardioprotection induced by exercise, so as to improve the endurance of cardiomyocytes to ischemia and hypoxia, resulting in less severe MIRI. Future studies may combine measuring HSPs levels with other related signaling elements such that the cardioprotective mechanism of exercise can be further elucidated.

In this study, histomorphology, blood biochemistry, TUNEL staining and cardiomyocyte TNF- $\alpha$, caspase- 3 , and $\mathrm{Bcl}-2$ expression were used to measure the severity of MIRI. The results proved that swimming for $3 \mathrm{~h}$ daily for 4 continuous weeks before MI decreased MI size, myocardial injury and cardiomyocyte apoptosis after myocardial I/R to achieve cardioprotective effects that were comparable to IPC. In the future, swimming training can be included in health promotion to decrease mortality rates due to cardiovascular diseases and improve the health of people.

\section{Acknowledgements}

Not applicable.

\section{Funding}

This study was supported by Ministry of Science and Technology (MOST; grant no. 109-2410-H-845-038) and partly supported by the University of Taipei (Taipei, Taiwan).

\section{Availability of data and materials}

The datasets used and/or analyzed during the present study are available from the corresponding author on reasonable request.

\section{Authors' contributions}

KWT designed the experiments, and wrote and revised the manuscript. CCL performed the primary experimental work and was involved in drafting the manuscript. CCL and CYT contributed to data acquisition and analysis. SKF and WCT made contributions to the conception and design of the study, manuscript revision, and confirmed the authenticity of all the raw data. All authors have read and approved the manuscript.

\section{Ethics approval and consent to participate}

The present study was approved by the Animal Experiment Committee of University of Taipei (Taipei, Taiwan; IACUC approval no. UT110001). The animals used in the study were managed in a humane manner in accordance with the Guide for the Care and Use of Laboratory Animals.

\section{Patient consent for publication}

Not applicable. 


\section{Competing interests}

The authors declare that they have no competing interests.

\section{References}

1. Balakumar P, Maung-UK and Jagadeesh G: Prevalence and prevention of cardiovascular disease and diabetes mellitus. Pharmacol Res 113: 600-609, 2016.

2. Nowbar AN, Gitto M, Howard JP, Francis DP and Al-Lamee R Mortality from ischemic heart disease. Circ Cardiovasc Qual Outcomes 12: e005375, 2019.

3. Patterson SW and Starling EH: On the mechanical factors which determine the output of the ventricles. J Physiol 48: 357-379, 1914.

4. Buja LM: Myocardial ischemia and reperfusion injury. Cardiovasc Pathol 14: 170-175, 2005.

5. Singhal AK, Symons JD, Boudina S, Jaishy B and Shiu YT: Role of endothelial cells in myocardial ischemia-reperfusion injury. Vasc Dis Prev 7: 1-14, 2010.

6. Sheehan FH, Doerr R, Schmidt WG, Bolson EL, Uebis R, von Essen R, Effert S and Dodge HT: Early recovery of left ventricular function after thrombolytic therapy for acute myocardial infarction: An important determinant of survival. J Am Coll Cardiol 12: 289-300, 1988.

7. Reeve JL, Duffy AM, O'Brien T and Samali A: Don't lose heart-therapeutic value of apoptosis prevention in the treatment of cardiovascular disease. J Cell Mol Med 9: 609-622, 2005.

8. Bolli R and Marbán E: Molecular and cellular mechanisms of myocardial stunning. Physiol Rev 79: 609-634, 1999.

9. Basso $\mathrm{C}$ and Thiene G: The pathophysiology of myocardial reperfusion: A pathologist's perspective. Heart 92: 1559-1562, 2006.

10. Ruiz-Meana M, Abellán A, Miró-Casas E and Garcia-Dorado D: Opening of mitochondrial permeability transition pore induces hypercontracture in $\mathrm{Ca}^{2+}$ overloaded cardiac myocytes. Basic Res Cardiol 102: 542-552, 2007

11. Argaud L, Loufouat J, Gateau-Roesch O, Gomez L, Robert D and Ovize M: Persistent inhibition of mitochondrial permeability transition by preconditioning during the first hours of reperfusion. Shock 30: 552-556, 2008.

12. Ishida T, Yarimizu K, Gute DC and Korthuis RJ: Mechanisms of ischemic preconditioning. Shock 8: 86-94, 1997.

13. Gross ER and Gross GJ: Ischemic preconditioning and myocardial infarction: An update and perspective. Drug Discov Today Dis Mech 4: 165-174, 2007.

14. Murry CE, Jennings RB and Reimer KA: Preconditioning with ischemia: A delay of lethal cell injury in ischemic myocardium. Circulation 74: 1124-1136, 1986

15. Vegh A, Szekeres L and Parratt JR: Transient ischaemia induced by rapid cardiac pacing results in myocardial preconditioning. Cardiovasc Res 25: 1051-1053, 1991.

16. Cumming DV, Heads RJ, Brand NJ, Yellon DM and Latchman DS: The ability of heat stress and metabolic preconditioning to protect primary rat cardiac myocytes. Basic Res Cardiol 91: 79-85, 1996.

17. Huang CH, Kim SJ, Ghaleh B, Kudej RK, Shen YT, Bishop SP and Vatner SF: An adenosine agonist and preconditioning shift the distribution of myocardial blood flow in conscious pigs. Am J Physiol 276: H368-H375, 1999.

18. Schott RJ, Rohmann S, Braun ER and Schaper W: Ischemic preconditioning reduces infarct size in swine myocardium. Circ Res 66: 1133-1142, 1990.

19. Liu GS, Thornton J, Van Winkle DM, Stanley AW, Olsson RA and Downey JM: Protection against infarction afforded by preconditioning is mediated by A1 adenosine receptors in rabbit heart. Circulation 84: 350-356, 1991.

20. $\mathrm{Li} \mathrm{Y}$ and Kloner RA: The cardioprotective effects of ischemic 'preconditioning' are not mediated by adenosine receptors in rat hearts. Circulation 87: 1642-1648, 1993.

21. Sumeray MS and Yellon DM: Ischaemic preconditioning reduces infarct size following global ischaemia in the murine myocardium. Basic Res Cardiol 93: 384-390, 1998.

22. Wilmore JH: Aerobic exercise and endurance: Improving fitness for health benefits. Phys Sportsmed 31: 45-51, 2003.

23. Swain DP and Franklin BA: Comparison of cardioprotective benefits of vigorous versus moderate intensity aerobic exercise. Am J Cardiol 97: 141-147, 2006.
24. Khot UN, Khot MB, Bajzer CT, Sapp SK, Ohman EM, Brener SJ, Ellis SG, Lincoff AM and Topol EJ: Prevalence of conventional risk factors in patients with coronary heart disease. JAMA 290: 898-904, 2003

25. Lawson WE, Hui JC, Zheng ZS, Burgen L, Jiang L, Lillis O, Oster Z, Soroff H and Cohn P: Improved exercise tolerance following enhanced external counterpulsation: cardiac or peripheral effect? Cardiology 87: 271-275, 1996.

26. Demirel HA, Powers SK, Zergeroglu MA, Shanely RA, Hamilton K, Coombes J and Naito H: Short-term exercise improves myocardial tolerance to in vivo ischemia-reperfusion in the rat. J Appl Physiol (1985) 91: 2205-2212, 2001.

27. Perrault $\mathrm{H}$ and Turcotte RA: Exercise-induced cardiac hypertrophy. Fact or fallacy? Sports Med 17: 288-308, 1994.

28. Jin H, Yang R, Li W, Lu H, Ryan AM, Ogasawara AK, Van Peborgh J and Paoni NF: Effects of exercise training on cardiac function, gene expression, and apoptosis in rats. Am J Physiol Heart Circ Physiol 279: H2994-H3002, 2000.

29. McElroy CL, Gissen SA and Fishbein MC: Exercise-induced reduction in myocardial infarct size after coronary artery occlusion in the rat. Circulation 57: 958-962, 1978.

30. Bowles DK, Farrar RP and Starnes JW: Exercise training improves cardiac function after ischemia in the isolated, working rat heart. Am J Physiol 263: H804-H809, 1992.

31. Gul M, Demircan B, Taysi S, Oztasan N, Gumustekin K, Siktar E, Polat MF, Akar S, Akcay F and Dane S: Effects of endurance training and acute exhaustive exercise on antioxidant defense mechanisms in rat heart. Comp Biochem Physiol A Mol Integr Physiol 143: 239-245, 2006.

32. Freimann S, Scheinowitz M, Yekutieli D, Feinberg MS, Eldar M and Kessler-Icekson G: Prior exercise training improves the outcome of acute myocardial infarction in the rat: Heart structure, function, and gene expression. J Am Coll Cardiol 45: 931-938, 2005

33. Ozturk N, Olgar Y, Er H, Kucuk M and Ozdemir S: Swimming exercise reverses aging-related contractile abnormalities of female heart by improving structural alterations. Cardiol J 24: 85-93, 2017.

34. Nagaraja HS and Jeganathan PS: Forced swimming stress-induced changes in the physiological and biochemical parameters in albino rats. Indian J Physiol Pharmacol 43: 53-59, 1999.

35. Popgeorgiev N, Sa JD, Jabbour L, Banjara S, Nguyen TTM, Akhavan-E-Sabet A, Gadet R, Ralchev N, Manon S, Hinds MG, et al: Ancient and conserved functional interplay between Bcl-2 family proteins in the mitochondrial pathway of apoptosis. Sci Adv 6: eabc4149, 2020.

36. Chou PL, Chen KH, Chang TC and Chien CT: Repetitively hypoxic preconditioning attenuates ischemia/reperfusion-induced liver dysfunction through upregulation of hypoxia-induced factor-1 alpha-dependent mitochondrial Bcl-xl in rat. Chin J Physiol 63: 68-76, 2020.

37. Murphy MP and Hartley RC: Mitochondria as a therapeutic target for common pathologies. Nat Rev Drug Discov 17: 865-886, 2018

38. Jiang T, Ma X, Chen H, Jia H and Xiong Y: Diazepam ameliorated myocardialischemia-reperfusioninjuryviainhibition ofC-Cchemokine receptor type 2/Tumor necrosis factor-alpha/Interleukins and Bcl-2-associated X protein/Caspase-3 pathways in experimental rats. J Vet Med Sci 83: 1965-1976, 2021.

39. Verboven M, Cuypers A, Deluyker D, Lambrichts I, Eijnde BO, Hansen D and Bito V: High intensity training improves cardiac function in healthy rats. Sci Rep 9: 5612, 2019.

40. Clark JD, Gebhart GF, Gonder JC, Keeling ME, and Kohn DF: The 1996 guide for the care and use of laboratory animals. ILAR Journal 38: 41-48, 1997.

41. Gazdag P, Oravecz K, Acsai K, Demeter-Haludka V, Ördög B, Szlovák J, Kohajda Z, Polyák A, Barta BA, Oláh A, et al: Increased $\mathrm{Ca}^{2+}$ content of the sarcoplasmic reticulum provides arrhythmogenic trigger source in swimming-induced rat athlete's heart model. Sci Rep 10: 19596, 2020.

42. Lee HW, Han TH, Yi KJ, Choi MC, Lee SY and Ryu PD: Time course of diurnal rhythm disturbances in autonomic function of rats with myocardial infarction. Auton Neurosci 179: 28-36, 2013

43. Zhao C, Yin M, Li F, Ling W, Luo C and Qin S: Mechanisms of Paeoniflorin against myocardial ischemia reperfusion injury based on network pharmacology. Mater Exp 11: 1505-1515, 2021.

44. El-Shitany NA, Tolba OA, El-Shanshory MR and El-Hawary EE: Protective effect of carvedilol on adriamycin-induced left ventricular dysfunction in children with acute lymphoblastic leukemia. J Card Fail 18: 607-613, 2012. 
45. Sabatasso S, Mangin P, Fracasso T, Moretti M, Docquier M and Djonov V: Early markers for myocardial ischemia and sudden cardiac death. Int J Legal Med 130: 1265-1280, 2016.

46. Thornberry NA and Lazebnik Y: Caspases: Enemies within. Science 281: 1312-1316, 1998.

47. Guski H, Meerson FZ and Wassilew G: Comparative study of ultrastructure and function of the rat heart hypertrophied by exercise or hypoxia. Exp Pathol 20: 108-120, 1981.

48. Yellon DM and Hausenloy DJ: Myocardial reperfusion injury N Engl J Med 357: 1121-1135, 2007.

49. Frank A, Bonney M, Bonney S, Weitzel L, Koeppen M and Eckle T: Myocardial ischemia reperfusion injury: From basic science to clinical bedside. Semin Cardiothorac Vasc Anesth 16 123-132, 2012

50. Pluijmert NJ, Bart CI, Bax WH, Quax PH and Atsma DE: Effects on cardiac function, remodeling and inflammation following myocardial ischemia-reperfusion injury or unreperfused myocardial infarction in hypercholesterolemic APOE* 3-Leiden mice. Sci Rep 10: 16601, 2020.

51. Hong XY, Hong X, Gu WW, Lin J and Yin WT: Cardioprotection and improvement in endothelial-dependent vasodilation during late-phase of whole body hypoxic preconditioning in spontaneously hypertensive rats via VEGF and endothelin-1. Eur J Pharmacol 842: 79-88, 2019.

52. Bolli R: The late phase of preconditioning. Circ Res 87: 972-983, 2000.

53. Marini M, Lapalombella R, Margonato V, Ronchi R, Samaja M Scapin C, Gorza L, Maraldi T, Carinci P, Ventura C and Veicsteinas A: Mild exercise training, cardioprotection and stress genes profile. Eur J Appl Physiol 99: 503-510, 2007.

54. Labarca G, Gower J, Lamperti L, Dreyse J and Jorquera J: Chronic intermittent hypoxia in obstructive sleep apnea: A narrative review from pathophysiological pathways to a precision clinical approach. Sleep Breath 24: 751-760, 2020.

55. Sanderson JE, Fang F, Lu M, Ma CY and Wei YX: Obstructive sleep apnoea, intermittent hypoxia and heart failure with a preserved ejection fraction. Heart 107: 190-194, 2021.

56. Nanduri J and Nanduri RP: Cellular mechanisms associated with intermittent hypoxia. Essays Biochem 43: 91-104, 2007.

57. Chen L, Shi D and Guo M: The roles of PKC-delta and PKC-epsilon in myocardial ischemia/reperfusion injury. Pharmacol Res 170: 105716, 2021.

58. Radak Z, Chung HY and Goto S: Systemic adaptation to oxidative challenge induced by regular exercise. Free Radic Biol Med 44: 153-159, 2008

59. Powers SK, Deminice R, Ozdemir M, Yoshihara T, Bomkamp MP and Hyatt H: Exercise-induced oxidative stress: Friend or foe? J Sport Health Sci 9: 415-425, 2020

60. Soukhova-O'Hare GK, Ortines RV, Gu Y, Nozdrachev AD Prabhu SD and Gozal D: Postnatal intermittent hypoxia and developmental programming of hypertension in spontaneously hypertensive rats: The role of reactive oxygen species and $\mathrm{L}-\mathrm{Ca}^{2+}$ channels. Hypertension 52: 156-162, 2008.

61. Boulghobra D, Coste F, Geny B and Reboul C: Exercise training protects the heart against ischemia-reperfusion injury: A central role for mitochondria? Free Radic Biol Med 152: 395-410, 2020

62. Lee MG, Park KS, Kim DU, Choi SM and Kim HJ: Effects of high-intensity exercise training on body composition, abdominal fat loss, and cardiorespiratory fitness in middle-aged Korean females. Appl Physiol Nutr Metab 37: 1019-1027, 2012.

63. Pattwell DM, McArdle A, Morgan JE, Patridge TA and Jackson MJ: Release of reactive oxygen and nitrogen species from contracting skeletal muscle cells. Free Radic Biol Med 37: 1064-1072, 2004.

64. McArdle A, van der Meulen J, Close GL, Pattwell D, Van Remmen H, Huang TT, Richardson AG, Epstein CJ, Faulkner JA and Jackson MJ: Role of mitochondrial superoxide dismutase in contraction-induced generation of reactive oxygen species in skeletal muscle extracellular space. Am J Physiol Cell Physiol 286: C1152-C1158, 2004.

65. Rinaldi B, Corbi G, Boccuti S, Filippelli W, Rengo G, Leosco D, Rossi F, Filippelli A and Ferrara N: Exercise training affects age-induced changes in SOD and heat shock protein expression in rat heart. Exp Gerontol 41: 764-770, 2006.

66. Dasgupta A, Wu D, Tian L, Xiong PY, Dunham-Snary KJ Chen KH, Alizadeh E, Motamed M, Potus F, Hindmarch CCT and Archer SL: Mitochondria in the pulmonary vasculature in health and disease: Oxygen-sensing, metabolism, and dynamics. Compr Physiol 10: 713-765, 2020.
67. Siu PM, Bryner RW, Martyn JK and Always SE: Apoptotic adaptations from exercise training in skeletal and cardiac muscles. FASEB J 18: 1150-1152, 2004.

68. O'Brien PJ, Smith DE, Knechtel TJ, Marchak MA, Pruimboom-Brees I, Brees DJ, Spratt DP, Archer FJ, Butler P, Potter AN, et al: Cardiac troponin I is a sensitive, specific biomarker of cardiac injury in laboratory animals. Lab Anim 40: 153-171, 2006.

69. Evran B, Karpuzoğlu H, Develi S, Kalaz EB, Soluk-Tekkeşin M, Olgaç V, Doğru-Abbasoğlu S and Uysal M: Effects of carnosine on prooxidant-antioxidant status in heart tissue, plasma and erythrocytes of rats with isoproterenol-induced myocardial infarction. Pharmacol Rep 66: 81-86, 2014.

70. Hausenloy DJ, Schulz R, Girao H, Kwak BR, De Stefani D, Rizzuto R, Bernardi P and Di Lisa F: Mitochondrial ion channels as targets for cardioprotection. J Cell Mol Med 24: 7102-7114, 2020.

71. Marcil M, Bourduas K, Ascah A and Burelle Y: Exercise training induces respiratory substrate-specific decrease in $\mathrm{Ca}^{2+}$-induced permeability transition pore opening in heart mitochondria. Am J Physiol Heart Circ Physiol 290: H1549-H1557, 2006.

72. Kavazis AN, McClung JM, Hood DA and Powers SK: Exercise induces a cardiac mitochondrial phenotype that resists apoptotic stimuli. Am J Physiol Heart Circ Physiol 294: H928-H935, 2008.

73. Mnafgui K, Hajji R, Derbali F, Khlif I, Kraiem F, Ellefi H, Elfeki A, Allouche N and Gharsallah N: Protective effect of hydroxytyrosol Against cardiac remodeling after isoproterenol-induced myocardial infarction in rat. Cardiovasc Toxicol 16: 147-155, 2016.

74. Leite CF, Lopes CS, Alves AC, Fuzaro CS, Silva MV, Oliveira LF, Garcia LP, Farnesi TS, Cuba MB, Rocha LB, et al: Endogenous resident c-kit cardiac stem cells increase in mice with an exercise-induced, physiologically hypertrophied heart. Stem Cell Res 15: 151-164, 2015

75. Pan C, Yuan Q and Xu F: Progress in cardiorespiratory ischemiareperfusion injury. In: Sudden Death. pp 79-92, 2021.

76. Rath PC and Aggarwal BB: TNF-induced signaling in apoptosis. J Clin Immunol 19: 350-364, 1999.

77. Cook AD, Lee MC, Saleh R, Khiew HW, Christensen AD, Achuthan A, Fleetwood AJ, Lacey DC, Smith JE, Förster I and Hamilton JA: TNF and granulocyte macrophage-colony stimulating factor interdependence mediates inflammation via CCL17. JCI Insight 3: e99249, 2018.

78. Sheikh MS and Huang Y: Death receptor activation complexes: It takes two to activate TNF receptor 1. Cell Cycle 2: 550-552,2003.

79. Balzano T, Arenas YM, Dadsetan S, Forteza J, Gil-Perotin S, Cubas-Nuñez L, Casanova B, Gracià F, Varela-Andrés N, Montoliu C, et al: Sustained hyperammonemia induces TNF- $\alpha$ IN Purkinje neurons by activating the TNFR1-NF- $\kappa \mathrm{B}$ pathway. J Neuroinflammation 17: 70, 2020.

80. Takeshita M, Tani T, Harada S, Hayashi H, Itoh H, Tajima H, Ohnishi I, Takamura H, Fushida S and Kayahara M: Role of transcription factors in small intestinal ischemia-reperfusion injury and tolerance induced by ischemic preconditioning. Transplant Proc 42: 3406-3413, 2010

81. Huldani, Pattelongi I, Massi MN, Idris I, Bukhari A, Widodo ADW, Uinarni H, Carmelita AB, Trisia A, Gunma S, Prayudhistya BKA and Achmad H: Cortisol, IL-6, TNF Alfa, Leukocytes and DAMP on Exercise. Sys Rev Pharm 11: 474-485, 2020.

82. Wertz IE: TNFR1-activated NF- $\mathrm{BB}$ signal transduction: Regulation by the ubiquitin/proteasome system. Curr Opin Chem Biol 23: 71-77, 2014

83. Valen G: The basic biology of apoptosis and its implications for cardiac function and viability. Ann Thorac Surg 75: S656-S660, 2003.

84. Ji HB, Zhai QW, Liu XY and Zheng ZC: Transcription regulation of bcl-2 gene. Sheng Wu Hua Xue Yu Sheng Wu Wu Li Xue Bao (Shanghai) 32: 95-99, 2000.

85. Yaoita H, Ogawa K, Maehara K and Maruyama Y: Attenuation of ischemia/reperfusion injury in rats by a caspase inhibitor. Circulation 97: 276-281, 1998.

86. Shimamoto A, Matsuo E, Kaneda S, Ito A, Kawaguchi K and Takao M: Heat shock protein 70 performs as pharmacological preconditioning to protect against lung ischemia reperfusion injury through toll-like receptor 4 signaling. J Heart Lung Transplant 40: S69, 2021.

87. Mitra S, Dasgupta R and Bagchi A: Heat shock proteins and their associated oxidative stress-induced heart disease. Modulation of Oxidative Stress in Heart Disease, 215-235, 2019. 
88. Shamsi MM,Hassan ZM and Gharakhanlou R: Exercise-induced chaperokine activity of hsp70: Possible role in chronic diseases. In: Chaperokine Activity of Heat Shock Proteins. Springer, Cham, pp193-209, 2019.

89. Milne KJ, Thorp DB, Krause M and Noble EG: Core temperature is a greater influence Than endogenous $17 \beta$-estradiol on the exercise-induced accumulation of myocardial heat shock protein mRNA. Can J Physiol Pharmacol 89: 855-860, 2011.

90. Liu X, Zhang C, Zhang C, Li J, Guo W, Yan D, Yang C, Zhao J, Xia T, Wang Y, et al: Heat shock protein 70 inhibits cardiomyocyte necroptosis through repressing autophagy in myocardial ischemia/reperfusion injury. In Vitro Cell Dev Biol Anim 52: 690-698, 2016

91. Rani N, Bharti S, Manchanda M, Nag TC, Ray R, Chauhan SS, Kumari S and Arya DS: Regulation of heat shock Proteins 27 and $70, \mathrm{p}-\mathrm{Akt} / \mathrm{p}$-eNOS and MAPKs by naringin dampens myocardial injury and dysfunction in vivo after ischemia/reperfusion. PLoS One 8: e82577, 2013.
92. Wu J, Chen S, Liu Y, Liu Z, Wang D and Cheng Y: Therapeutic perspectives of heat shock proteins and their protein-protein interactions in myocardial infarction. Pharmacol Res 160: 105162,2020

93. Hsu SF, Hsu CC, Cheng BC and Lin CH: Cathepsin B is involved in the heat shock induced cardiomyocytes apoptosis as well as the anti-apoptosis effect of HSP-70. Apoptosis 19: 1571-1580, 2014.

c) (i) $\odot$ This work is licensed under a Creative Commons Attribution-NonCommercial-NoDerivatives 4.0 International (CC BY-NC-ND 4.0) License. 